\title{
ENERGY EFFICIENCY IN GASOLINE DIRECT INJECTION ENGINES
}

\author{
GUIDO MARSEGLIA \& CARLO M. MEDAGLIA \\ Research Department, Link Campus University of Rome, Italy
}

\begin{abstract}
The growing awareness about the environmental impact of human activities and their influence on the increased concentrations of greenhouse gases (GHGs) has recently affected research efforts in the transportation field. Knocking in gasoline direct ignition (GDI) engine, is a kind of abnormal combustion that can restrict engine energy efficiency. It can also lead to permanent engine damage, under specific operating conditions. This paper focuses on the state of the art of engine knock research, considering the causes, influencing aspects, effects and methodology to predict and to reduce the probability of occurrence of this phenomenon. We present some examples of experimental procedures that were followed to analyze this event, through visualization images that can be supported by numerical activity, consisting of fluid dynamic simulation of the combustion process. Different systems to measure engine knock intensity and some mathematical models to predict abnormal combustion, in order to improve engine performance, are analyzed. Finally, in this work we try to give new perspectives for future research, through the use of different techniques to achieve knocking reduction. Keywords: abnormal combustion, direct injection engines, energy efficiency, environmental impact, gasoline powered engines, transportation.
\end{abstract}

\section{INTRODUCTION}

The impact of energy conversion processes on the environment has been increasingly relevant, because of the growing awareness of the effects of climate change on human living. In particular, the optimization of performance and the reduction of pollutant emissions from internal combustion engines have become important priorities, as a consequence of the spreading concern about the availability of fossil fuel reserves, and more and more stringent regulations on vehicle emissions at homologation [1].

In recent years, researchers and automotive industries have mainly focused on the analysis of thermo-fluid dynamic and chemical processes, studying the processes within the combustion chamber that are strongly related to engine performance in an internal combustion engine. In fact, while some zero-emission technologies are under investigation and development [2], internal combustion engines will continue being the most diffused powertrains for cars in the near future. A good balance between the reduction of fuel consumption and the improvement of performance is, today, the fundamental goal in both the spark ignition (SI) or compression engine (CI) engine [1], [3]-[5]. Parameters such as inlet pressure and temperature, spark timing, compression ratio, equivalence ratio and exhaust gas recirculation (EGR) are strongly linked to energetic engine efficiency. As regards the automotive market in Europe, Japan and North America, the projections foresee an average growth of GDI engine penetration, which will triple between 2010 and 2020 [6].

The injection strategy within the combustion chamber represents one of the most relevant aspects influencing both the power output and environmental impact of modern engines [1], [7].

A better fuel economy with respect to the port-fuel injection (PFI) system is achieved in the GDI system through greater flexibility to load changes, reduced tendency to abnormal combustion (especially knock) and reduction of both pumping and heat losses [1], [8]. Combustion evolution is strongly related to the mixture distribution in the combustion 
chamber. The detailed analysis of these processes is a key aspect in the possibility of having a complete ignition of the charge; namely, what can be considered as normal combustion [9][11]. Uncontrolled mixture formations are responsible for knock occurrence. Abnormal combustions verify when self-ignition develops around the in-cylinder end-gas zone of the charge, not yet reached by the main flame front [1], [12]-[14]. Of these, engine knock is the most known phenomenon. Abnormal combustion can lead to engine knock, as a function of the temperature and pressure of the end gases' evaluation. Knocking constrains the performance of a SI engine, because it limits exceeding certain values of the compression ratio and spark advance [1], [15].

\section{METHODOLOGY}

This phenomenon generates pressure waves, producing metallic ringing sounds, different with respect to the mute sound produced during normal combustion. In Fig. 1(a) and 1(b); respectively, we report examples of in-cylinder pressure obtained under no-knocking and knocking conditions. The images clearly underline the typical ripple of pressure recorded from the knocking type of combustion, with respect to normal combustion.

When knocking occurs over a long period of time, it can cause some undesirable damage to the engine component: cylinder head erosion, piston crow and top land erosion, piston melting, and/or breakage of piston rings [3].

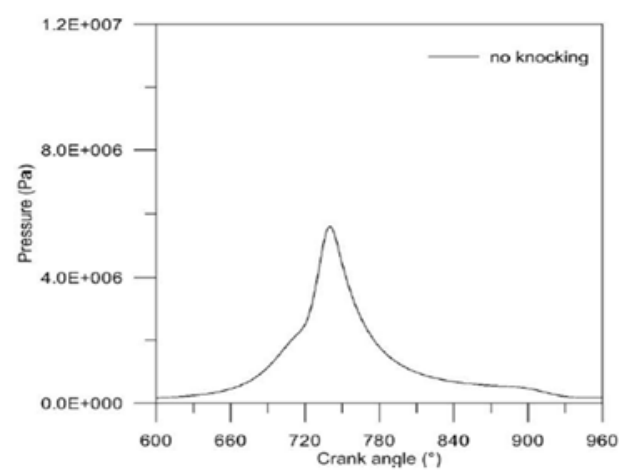

(a)

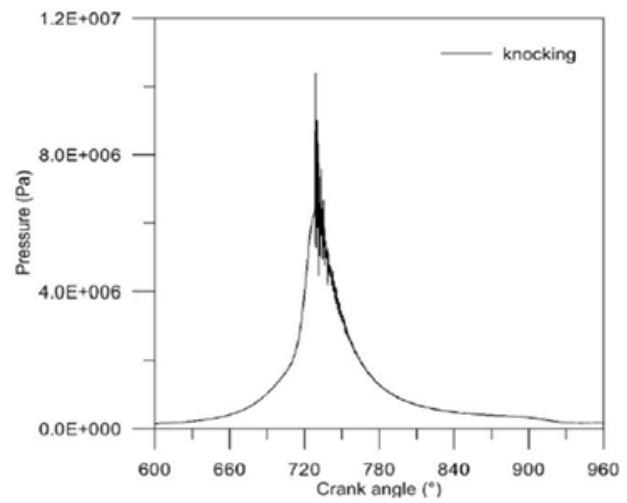

(b)

Figure 1: (a) Typical in-cylinder pressure cycles under knock; and (b) No-knock conditions [14]. 


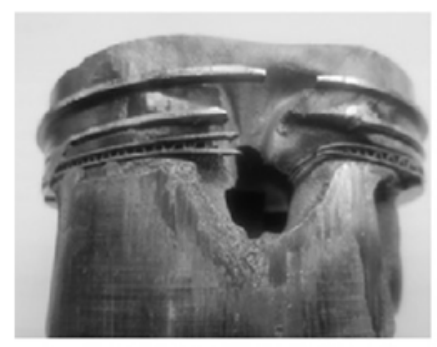

Piston melt

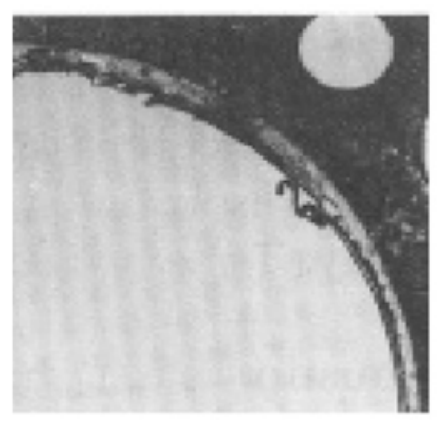

Gasket leakage
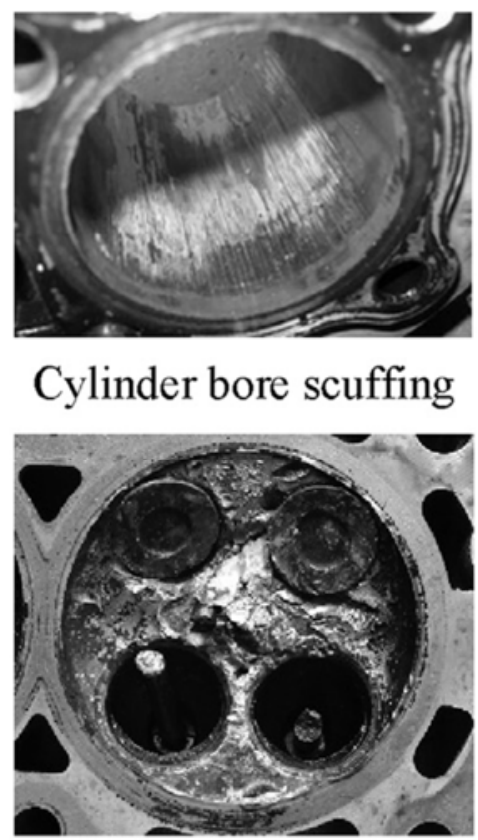

Cylinder head erosion

Figure 2: Conventional knocking-related damages [3].

Fig. 2 shows an example of some of these damages. Under knocking conditions, there is also preferentially a rise in air pollution, engine specific fuel consumption (SFC) and noise emissions [16]-[18]. Actually, complete knowledge about the main aspects that influence knock evolution can be of great benefit with respect to the next emission standard, as well as reducing development costs. Predicting knock is very complicated; for these reasons, it is necessary to analyse in detail the processes occurring within the combustion chamber [15], [18], [20], [21].

From this perspective, a synergic analysis between experimental and numerical research can be a precious tool, in order to understand the causes of engine knock and to predict the occurrence of this phenomenon. Due to its complexity, knock prediction represents a great challenge to designers and researchers [22]-[24].

It is possible to use various methods to predict and detect knocking [15], [25], [26] by means of different experimental techniques: for example based on in-cylinder pressure analysis, or vibration signals [27], [28] or using time frequency analysis signal processing [29]. In other applications on knock diagnostics, the ionization probe signals are correlated with the pressure signals in the auto-ignition and burned gas area [30], [31].

To better understand the phenomena involved, scientists usually use advanced laser diagnostics and sample laser techniques. Knocking can also be detected by monitoring exhaust gas temperature [32].

To calculate a quantification of the intensity of the knock, today we use various indices. The most common are based on the calculation of:

Maximum amplitude of pressure oscillations (MAPOs), related to the peak of the pressure oscillations due to engine knock: 


$$
\text { WAFQ }=\text { nux }\left\{\mathbb{F}_{\theta_{i}}^{Q}+\varepsilon\right.
$$

or the integral of modulus of pressure gradient (IMPG), related to the modulus of the pressure gradient:

$$
I M P G=\frac{1}{W} \sum_{1}^{W} \int_{\theta_{3}}^{\theta_{2}+\varepsilon} \frac{|d p|}{|d \theta|} d \theta
$$

or the integral of modulus of pressure oscillations (IMPOs), related to the high frequency oscillations of the cylinder pressure signal (including noise):

$$
\text { INPO }=\frac{1}{N} \sum_{1}^{W} \int_{\theta_{i}}^{\theta_{1}+\tau}[D] d \theta
$$

where $N$ is the number of computed cycles, $\theta_{0}$ is the crank angle that corresponds to the initial time of the range of calculation, $\zeta$ is the amplitude of the window of calculation, and $\hat{p}$ is the filtered in-cylinder pressure [15].

It is also possible to use other indexes like the Dimensionless Knock Indicator (DKI), which depends on the ratio between IMPO and MAPO, and the Logarithmic Knock Intensity (LKI), that is based on the average energy calculation [33].

\section{KNOCK VISUALIZATION RESEARCH}

Examples of optical images acquired during knocking conditions are shown in Fig. 3. The exhaust and intake valves are located in the upper and lower regions of the image, respectively; the spark plug is in the centre of the cylinder and the injector position is represented by means of the green circle [26]. The optical area detected from a high-speed camera is clearly represented in the image. Fig. 3 shows an image sequence at different crank angle degrees (CAD) during a knocking engine cycle [26]. At different events before top dead centre (BTDC), it is clearly evident that the hot spots arise at the downer of the frame, generating the auto-ignition zone. The auto-ignition region moves towards the centre of the chamber, near the main flame front, as shown at $8.6^{\circ} \mathrm{CAD}$ and $6.0^{\circ} \mathrm{CAD}$ BTDC. Finally, the end-gas zone is burned completely at $0.6^{\circ} \mathrm{CAD}$ BTDC and $2.1^{\circ} \mathrm{CAD}$ after top dead centre (ATDC) [26].

Another possibility to avoid favourable knocking conditions, and at the same time, to reduce emissions of GDI engines with further lowered cost and a simple system can be recently seen in the splitting of the injection into two or more events. Also, the start of injection time is fundamental: if the first injection occurs during the intake stroke and the second injection is made during compression, the knock is suppressed in the low-speed range and soot emissions are also reduced. The benefits to the engine performance, in terms of knock reduction deriving from the split injection, was recently investigated [34] by means of the use of 3D Computational Fluid Dynamics (CFD). Numerical simulation can give additional details on the flame front propagation and direction, and on the equivalence ratio distribution, comparing a case of single injection during knocking conditions and a case of split injection under no-knocking conditions.

\section{CONCLUSIONS}

Within this paper, a review of the energy conversion process taking place in GDI engines is analysed, highlighting the advantages of the modern GDI with respect to the PFI engines. 

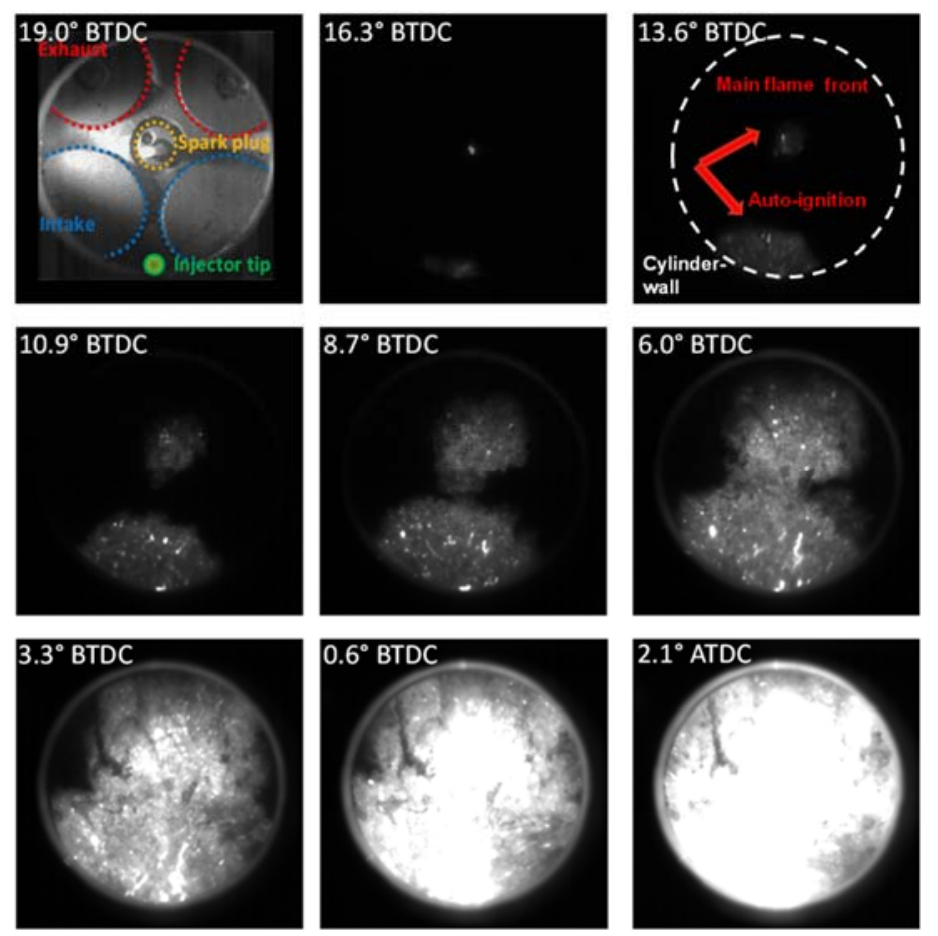

Figure 3: Flame front propagation during a knocking cycle [26].

The research underlines the most important current methods used to express a quantification of knocking intensity, strongly related to an engine's energy efficiency: different indexes are used to measure knock, such as MAPO, IMPG and IMPO. In the combustion evolution process, experimental optical diagnostic techniques are fundamental in the flame front evolution, during auto-ignition. A synergic experimental and numerical activity currently allows us to compare the experimental images of the flame front propagation with those obtained from the numerical simulations, to analyse in detail the correlation between the thermo-fluid dynamic features and the evolution of the combustion process.

\section{REFERENCES}

[1] Marseglia, G., Costa, M., Catapano, F., Sementa, P. \& Vaglieco, B.M., Study about the link between injection strategy and knock onset in an optically accessible multicylinder GDI engine. Energy Conversion and Management, 134, pp. 1-19, 2017.

[2] Carrese, S., Giacchetti, T., Nigro, M. \& Patella, S.M., An innovative car sharing electric vehicle system: An Italian experience. WIT Transactions on the Built Environment, vol. 176, WIT Press: Southampton and Boston, pp. 245-252, 2018.

[3] Heywood, J.B., Internal Combustion Engine Fundamentals, McGraw Hill, 1988.

[4] Nakama, K., Kusaka, J. \& Daisho, Y., Study of knock control in small gasoline engines by multi-dimensional simulation. Society of Automotive Engineers (SAE) Technical Paper \#2006-32-0034, 2006. 
[5] Garcia, A., Piqueras, P., Monsalve-Serrano, J. \& Lago Sari, R., Sizing a conventional diesel oxidation catalyst to be used for RCCI combustion under real driving conditions. Applied Thermal Engineering, 140, pp. 62-72, 2018.

[6] Whitaker, P., Powertrain strategies for the 21st century, AVL, 2015. www.umtri.umich.edu/sites/default/files/Paul.Whitaker.

[7] Wang, Z., Wiszynski, M.L., Xu, H., Abdullah, N.R. \& Piaszyk, J., Fuel injection and combustion study by the combination of mass flow rate and heat release rate with single and multiple injection strategies. Fuel Process Technology, 132, pp. 118-132, 2012.

[8] Zhao, H., Advanced Direct Injection Combustion Engine Technologies and Development. Vol. I: Gasoline and Gas Engines, Vol. II: Diesel Engines, Woodhead Publishing, 2010.

[9] Oh, H. \& Bae, C., Effects of the injection timing on spray and combustion characteristics in a spray-guided DISI engine under lean-stratified operation. Fuel, 107, pp. 225-235, 2013.

[10] Roy, M.K., Kawahara, N., Tomita, E. \& Fujitani, T., Jet-guided combustion characteristics and local fuel concentration measurements in a hydrogen direct injection spark-ignition engine. Proceedings of the Combustion Institute, 34(2), pp. 2977-2984, 2013.

[11] Oh, H., Bae, C., Park, J. \& Jeon, J., Effect of the multiple injection on stratified combustion characteristics in a spray-guided DISI engine. SAE Technical Paper \#2011-24-0059, 2011.

[12] Stan, C., Direct Injection Systems for Spark-Ignition and Compression-Ignition Engines, Society of Automotive Engineers (SAE) International, Order R-289, 2000.

[13] Costa, M., Catapano, F., Marseglia, G., Sorge, U., Sementa, P. \& Vaglieco, B.M., Experimental and Numerical Investigation of the Effect of Split Injections on the Performance of a GDI Engine Under Lean Operation, Society of Automotive Engineers (SAE) Technical Paper 2015-24-2413, 2015. DOI: 10.4271/2015-24-2413.

[14] Sorge, U., Simulazione multidimensionale ed ottimizzazione del processo di conversione dell'energia in motori ad iniezione diretta di benzina. $\mathrm{PhD}$ thesis, University Federico II of Naples, 2013. http://www.fedoa.unina.it/9457/1/ Sorge_Ugo_25.pdf. DOI: 10.6092/unina/fedoa/9457.

[15] Zhen, X., Wang, Y., Xu, S., Zhu, Y., Tao, C., Xu, T. \& Song, M., The engine knock analysis: An overview. Applied Energy, 92, pp. 628-636, 2012.

[16] Nates, R.J. \& Yates, A.D.B., Knock Damage Mechanisms in Spark-ignition Engines. Society of Automotive Engineers (SAE) Technical Paper \#942064, 1994.

[17] Fitton, J. \& Nates, R., Knock Erosion in Spark-ignition Engines. Society of Automotive Engineers (SAE) Technical Paper \#962102, 1996.

[18] Konig, G., Maly, R.R., Bradley, D., Lau, A.K.C. \& Sheppard, C.G.W., Role of Exothermic Centres on Knock Initiation and Knock Damage. Society of Automotive Engineers (SAE) Technical Paper \#902136, 1990.

[19] Terashima, H. \& Koshi, M., Mechanisms of strong pressure wave generation in endgas autoignition, during knocking combustion. Combustion and Flame, 162, pp. 19441956, 2015.

[20] Addepalli, S., Saw, O. \& Mallikarjuna, J., Effect of mixture distribution on combustion and emission characteristics in a GDI engine: a CFD analysis. Society of Automotive Engineers (SAE) Technical Paper \#2017-24-0036, 2017. 
[21] Song, J., Kim, T., Jang, J. \& Park, S., Effects of the injection strategy on the mixture formation and combustion characteristics in a DISI (direct injection spark ignition) optical engine. Energy, 93, pp. 1758-1768, 2015.

[22] Marseglia, G., Knock Onset and Soot Formation in Gasoline Direct Injection Engines: Issues for Future Development. PhD thesis: Istituto Motori \& Parthenope University of Naples, 2016.

[23] Merola, S.S., Tornatore, C. \& Irimescu, A., Cycle-resolved visualization of preignition and abnormal combustion phenomena in a GDI engine. Energy Conversion and Management, 127, pp. 380-391, 2016.

[24] Catapano, F., Sementa, P. \& Vaglieco, B.M., Characterization of knock tendency and onset in a GDI engine by means of conventional measurements and a non-conventional flame dynamics optical analysis. SAE International Journal of Engines, 10(5), 2017.

[25] Vafamehr, H., Cairns, A. \& Koupaie, M.M., The competing chemical and physical effects of transient fuel enrichment on heavy knock in an optical spark ignition engine. Society of Automotive Engineers (SAE) Technical Paper \#2017-01-0665, 2017. https://doi.org/10.4271/2017-01-0665.

[26] Catapano, F., Costa, M., Marseglia, G., Sementa, P. \& Sorge, U., Experimental and numerical investigation in a turbocharged GDI engine under knock condition by means of conventional and non-conventional methods. SAE International Journal of Engines, 8(2), pp. 437-446, 2015. DOI: 10.4271/2015-01-0397.

[27] Thomas, J.H., Dubuisson, B. \& Dillies-Peltier, M.A., Engine knock detection from vibration signals using pattern recognition. Meccanica, 32, pp. 431-439, 1997.

[28] Siano, D. \& D'agostino, D., Knock detection in SI engines by using the discrete wavelet transform of the engine block vibrational signals. Energy Procedia, 81, pp. 673-688, 2015.

[29] Samimy, B. \& Rizzoni, G., Mechanical signature analysis using time frequency signal processing: Application in internal combustion engine knock detection. Proceedings of the IEE, 84(9), pp. 1330-1343, 1996.

[30] Labuda, S., Sotton Bellenoue, J.M., Chernukho, A.P. \& Migoun, A.N., Application of ionization probes for diagnostic of knocking combustion. 7th Conference Mediterranean Combustion Symposium, Cagliari, 2011.

[31] Kinoshita, M., Saito, A., Mogi, K. \& Nakata, K., Study on ion current and pressure behavior with knocking in engine cylinder. JSAE Review, 21(4), pp. 483-488, 2000.

[32] Mohamed, A.Q., Exhaust gas temperature for knock detection and control in spark ignition engine. Energy Conversion and Management, 37, pp. 1383-1392, 1996.

[33] Hudson, C., Gao, X. \& Stone, R., Knock measurement for fuel evaluation in spark ignition engines. Fuel, 80, pp. 395-407, 2001.

[34] Costa, M., Sementa, P., Sorge, U., Catapano, F., Marseglia, G. \& Vaglieco, B.M., Split Injection in a GDI Engine Under Knock Conditions: An Experimental and Numerical Investigation. SAE Technical Paper \#2015-24-2432, 2015. DOI: 10.4271/2015-242432. 